\title{
CAPSULE PRODUCTION AND VIRULENCE AMONG STRAINS OF STAPHYLOCOCCUS AUREUS
}

\author{
Bill B. Wiley \\ Department of Microbiology \\ University of Utah College of Medicine \\ Salt Lake City, Utah 84112 \\ N. H. Maverakis \\ Department of Epidemiology \\ University of Michigan School of Public Health \\ Ann Arbor, Michigan 48104
}

In 1956, just after Price and Kneeland ${ }^{1}$ first reported the occurrence of a specific capsular reaction in a strain of mucoid $S$. aureus isolated after egg passage of a throat isolate with an A strain of influenza virus, we were searching about for an area of endeavor that might interest us. Their initial report was followed by a second one ${ }^{2}$ in which they seemed to downgrade the importance of their finding by reporting what they interpreted as a lack of specificity, owing to the fact that all of 39 isolates of $S$. aureus from clinical material exhibited specific capsular reactions with a single antiserum. We could not agree with their conclusion; this proved to be the stimulus that awakened our interest in the occurrence of encapsulation and its significance among strains of $S$. aureus.

Our first efforts in the field were concerned with the isolation of mucoid variants of $S$. aureus; we employed the technique of Bigger and colleagues." They cultivated staphylococci in broth that contained a fermentable carbohydrate, and maintained the cultures in this environment for up to two months. Periodic subcultivation to agar plates and subsequent testing of colonies for mucosity was used as a screening proceduce to obtain mucoid variants. With this procedure we obtained five mucoid strains of $S$. aureus. One strain, which originated from an infected sutured wound, was especially mucoid and was used to stimulate antibody production in rabbits and roosters. A long and vigorous immunization course was used, as described by Alexander and colleagues for the production of antiserum for use in the specific capsular reaction with Haemophilus influenzae. A positive specific capsular reaction obtained with the rooster hyperimmune serum and a negative reaction are shown in Figures $1 \mathrm{~A}$ and $1 \mathrm{~B}$ respectively.

A tendency to decry the finding of capsules on mucoid variants of $S$. aureus obtained by laboratory manipulation led to studies of the incidence of naturally occurring strains of encapsulated $S$. aureus and the natural occurrence of anticapsular antibodies. Healthy human blood donors from a rural area submitted to swabbing of their anterior nares and also donated samples of their plasma. The swabs were planted on mannitol salt plates and colonies were picked and placed in buffered nutrient glycerol broth for subsequent testing in the specific capsular reaction, in which we used a hyperimmune rabbit antistaphylococcus serum. We used the plasma samples of the donors in a specific capsular reaction test, using the known encapsulated $S$. aureus we had isolated. The results of these tests are shown in TABLE 1 . Of the 109 blood donors, $43 \%$ carried $S$. 


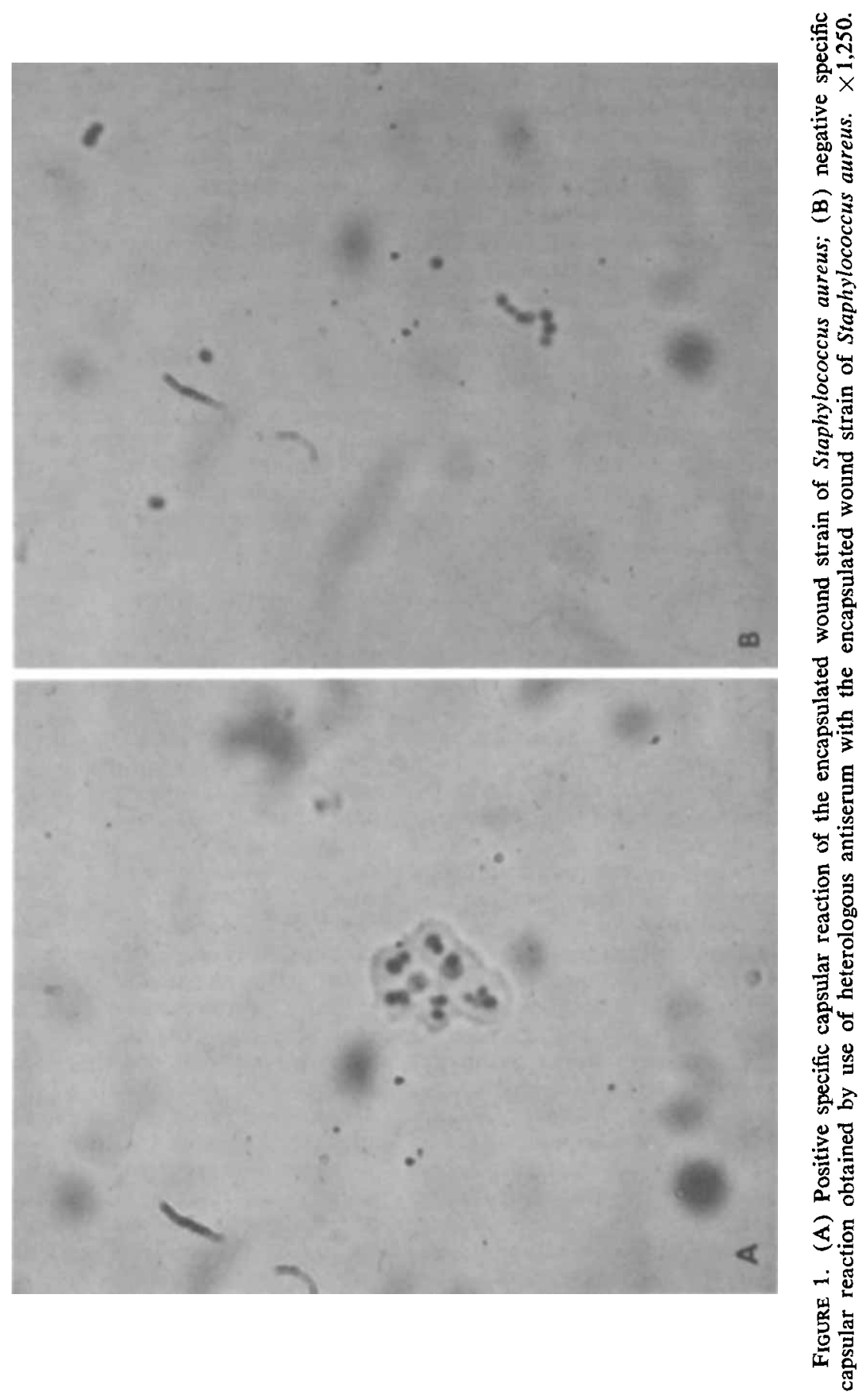


TABLE 1

Incidence of Staphylococcus Carriers Among 109 Blood Donors

\begin{tabular}{lcc}
\hline & Number & Percentage \\
\hline Nasal carriers & 47 & 43 \\
Carriers with encapsulated staphylococci $*$ & 21 & 44.7 \\
Carriers with nonencapsulated staphylococci $\dagger$ & 26 & 55.3 \\
\hline
\end{tabular}

* This was determined by production of a positive specific capsular reaction, using rooster antiwound $S$. aureus serum.

$\dagger$ This was determined by failure of rooster antiwound $S$. aureus serum to produce a positive specific capsular reaction.

aureus in their anterior nares. Of these staphylococcus carriers, $44.7 \%$ carried naturally occurring encapsulated $S$. aureus; this was evidenced by the positive specific capsular reactions they exhibited. The remaining $55.3 \%$ of the carriers carried either nonencapsulated $S$. aureus or encapsulated strains of different capsular types for which we had no antiserum. TABLE 2 presents the results of specific capsular reaction tests carried out on the serum of the blood donors. The incidence of anticapsular antibodies that reacted against the wound encapsulated strain of $S$. aureus was $80 \%$. Of the 47 donors who carried $S$. aureus, $37(78.7 \%)$ had anticapsular antibodies. Of the staphylococcus carriers in the study, $21.3 \%$ did not have anticapsular antibodies against the wound encapsulated $S$. aureus. Since such a high incidence of naturally occurring anticapsular antibodies had been revealed, it was decided to study a group of 50 sera from pediatric subjects that had originally been submitted for viral studies. The subjects ranged in age from 1 month to 13 years. None of the subjects 6 years old or under had anticapsular antibodies. As further confirmation of the high

TABLE 2

Incidence of Staphylococcal Anticapsular Antibodies in 109 Blood Donors

\begin{tabular}{lccc}
\hline & Number & $\begin{array}{c}\text { Precentage of } \\
\text { Blood Donors }\end{array}$ & $\begin{array}{c}\text { Percentage of } \\
\text { Carriers }\end{array}$ \\
\hline $\begin{array}{l}\text { Carriers with capsular } \\
\text { antibodies * }\end{array}$ & 37 & 34 & 78.7 \\
$\begin{array}{l}\text { Carriers without capsular } \\
\text { antibodies * }\end{array}$ & 10 & 96 & 21.3 \\
$\begin{array}{l}\text { Noncarriers with capsular } \\
\text { antibodies * }\end{array}$ & 50 & 11 & - \\
$\begin{array}{l}\text { Noncarriers without capsular } \\
\text { antibodies } \dagger\end{array}$ & 12 & 80 & - \\
$\begin{array}{c}\text { Total number of donors } \\
\text { with antibodies }\end{array}$ & 87 & 46 & - \\
\hline
\end{tabular}

* Numbers and percentages represent positive specific capsular reactions obtained using the mucoid wound encapsulated $S$. aureus and donor's serum.

$\dagger$ This was determined by failure of the donor's serum to elicit a positive specific capsular reaction using the wound mucoid encapsulated $S$. aureus. 
incidence of anticapsular antibodies in humans that reacted with the wound encapsulated strain, a group of 173 cord blood specimens submitted to the hematology division was examined, and a $48 \%$ incidence of anticapsular antibodies was found.

A test ${ }^{5}$ of virulence in embryonated hens' eggs, inspired by studies of Frappier and Sonea, ${ }^{6}$ was developed to study the virulence of naturally occurring encapsulated $S$. aureus strains. The test utilized intravenous injection of the eggs and an observation period of 5 days. The virulence of a group of naturally occurring encapsulated $S$. aureus strains from healthy carriers and a group of naturally encapsulated strains from hospitalized patients were compared in the virulence test. The results are shown in TABLE 3 . The $\operatorname{LD}_{50} \mathrm{~s}$ were calculated by the method of Miller and Tainter, ${ }^{7}$ and are expressed as the numbers of staphylococci that produced a $50 \%$ kill after a 5-day observation period. The $95 \%$ confidence limits, based on a normal distribution, are also shown. Within the groups differences in $L D_{50}$ were observable, but with the exception of the carrier strain P-28, there were no significant differences in virulence between the groups. The latter strain was heavily encapsulated and significantly more virulent than any of the other strains of $S$. aureus. The results showed the test of virulence in embryonated eggs to be a highly sensitive indicator of staphylococcal virulence.

There was a tendency for cultures of the original wound encapsulated strain to give rise to spontaneous nonmucoid variants, and these afforded an excellent opportunity to compare subjectively the capsular size as revealed in the specific capsular reaction and that of the parent organism, and to compare the egg virulence of the parent and the nonmucoid variant. In 4-hour broth cultures of the parent strain, capsules were well developed and well maintained by the

TABLE 3

LD $_{50}$ S and Phage Patterns of Hospital $S$. aureus Strains From Carriers and Patients

\begin{tabular}{|c|c|c|c|c|}
\hline Strain & Source & $\mathrm{LD}_{50} *$ & $\begin{array}{l}\text { 95\% Confidence } \\
\text { Limits }\end{array}$ & $\begin{array}{l}\text { Phage } \\
\text { Pattern }\end{array}$ \\
\hline P-28 & carrier & $\overrightarrow{14}$ & $1-24$ & nontypable \\
\hline L-35 & $"$ & 1,289 & $759-2,188$ & $53 / 77$ \\
\hline$W-31$ & $"$ & 1,779 & $1,024-3,091$ & $77 / 87$ \\
\hline L-29 & $"$ & 2,819 & $1,863-4,266$ & $52 / 52 \mathrm{~A} / 80 / 82$ \\
\hline M.30 & $"$ & 5,624 & $3,236-9,773$ & $3 \mathrm{~A} / 3 \mathrm{~B} / 3 \mathrm{C} / 55$ \\
\hline M-34 & $"$ & 56,240 & $30,200-104,800$ & $52 \mathrm{~A} / 80 / 82$ \\
\hline F-32 & $"$ & 58,890 & $29,520-107,200$ & $3 \mathrm{~A}$ \\
\hline S-14 & patient & 955 & $501-1,820$ & $7 / 42 \mathrm{E} / 53 / 54 / 77 / 81 / 82$ \\
\hline P.13 & $"$ & 1,000 & $531-1,863$ & $80 / 81 / 82$ \\
\hline D-1 & $"$ & 1,259 & $776-2,042$ & $80 / 81 / 82$ \\
\hline $\mathrm{C}-7$ & $"$ & 1,936 & $1,349-2,952$ & $82 / 3 \mathrm{C}$ \\
\hline A-18 & $"$ & 8,512 & $6,026-12,030$ & $47 / 53 / 77$ \\
\hline M-5 & $"$ & 21,880 & $14,660-33,120$ & $6 / 47 / 54$ \\
\hline $\mathrm{K}-27$ & $"$ & 60,260 & $29,520-123,100$ & $7 / 47 / 54 / 75 / 77$ \\
\hline
\end{tabular}

$* \mathrm{LD}_{50} \mathrm{~S}$ and $95 \%$ confidence limits are expressed as the number of organisms that produced a $50 \%$ kill after a 5 -day observation period. 
TABLE 4

LD $_{50}$ S of MucoId and Nonmucoid Variants

\begin{tabular}{|c|c|c|}
\hline Strain & $\mathrm{LD}_{50} *$ & $\begin{array}{l}\text { 95\% Confidence } \\
\text { Limits }\end{array}$ \\
\hline Wound mucoid & 250 & \pm 188 \\
\hline Wound nonmucoid & 10,000 & $\pm 8,280$ \\
\hline P-28 & 11 & \pm 6 \\
\hline P-28 grown in $5 \%$ antiserum & 60 & \pm 28 \\
\hline
\end{tabular}

* LD $D_{50}$ and $95 \%$ confidence limits are expressed as the number of organisms that produced a $50 \%$ kill after a 5 -day observation period.

organisms, while capsules on the nonmucoid variant were small fragmentary structures that disappeared spontaneously by 12 hours. Carrier strain P-28 also exhibited large capsules in the specific capsular reaction, and was the most virulent strain of $S$. aureus that we had isolated to date. It was decided to study the egg virulence of the mucoid wound and nonmucoid variant strains, and also to study the effect of growing an encapsulated variant in the presence of $5 \%$ capsular antiserum. It was assumed that the latter step would suppress capsule formation, which would possibly lead to the isolation of a nonencapsulated variant. Only the highly virulent strain P-28 was subjected to the antiserum treatment. The $\mathrm{LD}_{50}$ figures for these strains in embryonated hens' eggs are shown in TABLE 4. The egg virulence of the wound mucoid and nonmucoid variant differed significantly. Similarly, the effect of growth in $5 \%$ antiserum on strain P-28 was to decrease its virulence for embryonated eggs significantly.

To assess the relationship between capsular size, the amount of capsular material synthesized, and egg virulence, a technique used by Ehrenworth and Baer ${ }^{8}$ in studies of the pathogenicity of Klebsiella pneumoniae was used. Four naturally occurring encapsulated $S$. aureus strains were studied: specific capsular reactions were carried out on these strains at $0,4,12$, and 24 hours after inoculation into broth. At the same intervals viable counts and packed cell volumes were determined. Egg virulence tests were also done on 24-hour cultures of these same strains. The results of the specific capsular reactions and the viable count:packed cell volume ratios are presented in TABLE 5. A low ratio reflects a large packed cell volume relative to the viable count, and thus the presence of large capsules on the cells. As the ratio increases, it reflects a lower packed cell volume relative to the viable count, and thus smaller capsules. The subjective reading of the specific capsular reaction correlates well with the ratios. Strain $\mathrm{K}-1$ had a relatively high ratio initially, reflecting its small capsules, which seemed however to increase in size after 12 hours in the growth cycle. Strains WSCV and NB-1 were alike in possessing small capsules that were maintained for 4-8 hours, then tended to decrease. Strain P-28 had a low initial viable count:packed cell volume ratio; this reflected its large capsules, which were maintained well for 12 hours. The amount of capsular material released into the medium was estimated as a function of time by a hemagglutination inhibition test ${ }^{9}$ capable of detecting $2-4 \mu \mathrm{g}$ capsular material. Strain P-28 liberated the most capsular material, which possibly showed that it had a higher rate of synthesis, since it maintained its capsules 
TABLe 5

Viable Count:Packed Cell Volume Ratios and Release of Capsular Material

\begin{tabular}{|c|c|c|c|c|}
\hline Strain & Time & $\begin{array}{c}\text { Viable } \\
\text { Count:Packed } \\
\text { Cell Volume } \\
\text { Ratio } \times \\
10^{3}\end{array}$ & $\begin{array}{c}\text { Capsular } \\
\text { Material } \\
\text { Released } †\end{array}$ & $\begin{array}{c}\text { Specific } \\
\text { Capsular } \\
\text { Reaction } \ddagger\end{array}$ \\
\hline K-1 & $\begin{array}{c}\text { hours } \\
0 \\
4 \\
8 \\
12 \\
24\end{array}$ & $\begin{array}{l}-\overline{198} \\
303 \\
358 \\
364\end{array}$ & $\begin{array}{r}\mu \mathrm{g} / \mathrm{ml} \\
0 \\
0 \\
0 \\
0 \\
100\end{array}$ & $\begin{array}{l}1+ \\
1+ \\
2+ \\
2+ \\
2+\end{array}$ \\
\hline Wound SCV & $\begin{array}{r}0 \\
4 \\
8 \\
12 \\
24\end{array}$ & $\begin{array}{l}\overline{187} \\
438 \\
461 \\
373\end{array}$ & $\begin{array}{r}0 \\
0 \\
0 \\
0 \\
133\end{array}$ & $\begin{array}{l}1+ \\
1+ \\
1+ \\
1+ \\
1+\end{array}$ \\
\hline NB-1 & $\begin{array}{r}0 \\
4 \\
8 \\
12 \\
24\end{array}$ & $\begin{array}{l}-\overline{265} \\
348 \\
332 \\
539\end{array}$ & $\begin{array}{r}0 \\
0 \\
0 \\
0 \\
80\end{array}$ & $\begin{array}{l}1+ \\
1+ \\
2+ \\
1+ \\
1+\end{array}$ \\
\hline P-28 & $\begin{array}{r}0 \\
4 \\
8 \\
12 \\
24\end{array}$ & $\begin{array}{r}\overline{33} \\
167 \\
236 \\
300\end{array}$ & $\begin{array}{r}0 \\
40 \\
66 \\
133 \\
100\end{array}$ & $\begin{array}{l}4+ \\
3+ \\
2+ \\
2+ \\
1+\end{array}$ \\
\hline
\end{tabular}

* Packed cell volumes were measured after centrifugation for $30 \mathrm{~min}$ at $1000 \times g$ in an International Centrifuge Model SBV with number 233 head.

$\dagger$ Capsular material was estimated by means of a hemagglutination inhibition test described in Reference 9.

¥ Specific capsular reaction was tested with rooster anti-wound $S$. aureus serum.

well for up to 12 hours, whereas the others did not. These findings correlated with the results of the egg virulence tests carried out on these strains (TABLE 6). Strain K-1 was the least virulent, while strains WSCV and NB-1 were of intermediate virulence and strain P-28 was the most virulent of the group. Coagulase titrations correlated with virulence: strain P-28 produced the most free coagulase and $\mathrm{K}-1$ the least. Although admittedly the cultures were not grown in the presence of increased $\mathrm{CO}_{2}$, there were differences in the amount of rabbit red cell lysin elaborated by the various strains. Strain $\mathrm{K}-1$, the least virulent, produced the highest titer of lysin active on rabbit red cells, while the other strains produced little or no rabbit red cell lysin.

Virulence tests carried out with strains of $S$. epidermidis were often indeterminate, because the embryonated eggs resisted up to 8 million intravenously injected cells. A rather unusual staphylococcal strain, designated as 3961 , was 
coagulase-negative but occasionally exhibited capsules. Whether or not this strain was $S$. epidermidis or $S$. aureus was not established. It did not kill embryonated eggs when administered in high doses, but it could on occasion be cultured from injected eggs 5 days after inoculation. The pressure of other matters did not permit a thorough investigation of the behavior of this strain; perhaps one day we will return to studies of its behavior.

Since we had developed the egg virulence test, ${ }^{5}$ it seemed logical to attempt to evaluate the passive protective properties of serum that contained specific capsular antibodies. We simply modified the virulence test by running culture diluted in $b_{1}$ oth simultaneously with culture similarly diluted in antiserum. Thus, if the first dilution of the $L D_{50}$ was $1: 500$ in broth, for the protection test we diluted culture $1: 100$ in broth, and the final dilution of 1:500 was made in antiserum. One of the reasons that we did the test this way was our desire to keep the injection volume of $.05 \mathrm{ml}$ constant. Furthermore, it was considered unwise to traumatize the embryos further by attempting to preinject antiserum intravenously before giving the challenge inoculum. A great deal of difficulty was encountered initially with nonspecific deaths in the embryonated eggs, due to hemorrhages. It was later surmised that these could be occurring as a result of the activation of permeases in the antiserum through dilution after injection. When the sera were heated or globulin fractions were prepared from them, the nonspecific death rate fell to an acceptable $5 \%$. The results are shown in TABLE 7. The data shown have supported the conclusion that antisera that contain capsular antibodies do passively protect the embryonated egg significantly against up to $50 \mathrm{LD}_{50}$ doses of encapsulated $S$. aureus. It should be pointed out that the actual amount of antiserum injected per egg was $.04 \mathrm{ml}$ undiluted serum. To ascertain whether or not polysaccharide fractions prepared from culture supernatant fluids were capable of removing the passive protective properties of the antisera, absorption tests were carried out in which these crude polysaccharide fractions isolated after ethanol precipitation were used. TABLE 8 shows the results of this experiment: the polysaccharide fractions significantly removed protective properties from rabbit immune globulin and human globulin.

Up to this point, all of the work had been done with the wound mucoid strain of encapsulated $S$. aureus. Our laboratory showed that the wound mucoid strain and the RLM strain first described by Price and Kneeland ${ }^{1}$ were of the same capsular type, when we succeeded in producing a specific capsular reaction

TABLE 6

LD $D_{\text {sos }}$ of Naturally Encapsulated $S$. aureus Strains

\begin{tabular}{ccc}
\hline \hline Strain & LD $_{\mathbf{5 0}}^{*}$ & $\begin{array}{c}95 \% \text { Confidence } \\
\text { Limits }\end{array}$ \\
\hline $\begin{array}{l}\text { K-1 } \\
\text { Wound small capsular variant } \\
\text { NB-1 } \\
\text { P-28 }\end{array}$ & 40,000 & $\pm 22,204$ \\
& 7,000 & $\pm 3,024$ \\
& 7,000 & $\pm 2,220$ \\
& 11 & \pm 6 \\
\hline
\end{tabular}

* $\mathrm{LD}_{50} \mathrm{~S}$ and $95 \%$ confidence lmits are expressed as the number of organisms that produced a $50 \%$ kill after a 5 -day observation period. 
TABLE 7

Passive Protective Properties of Capsular Antibody

\begin{tabular}{lcc}
\hline \multicolumn{1}{c}{ Antiserum } & $\begin{array}{c}\text { Number of } \\
\text { LD sos Used } \\
\text { in Challenge }\end{array}$ & $\begin{array}{c}\text { Percent } \\
\text { Survival }\end{array}$ \\
\hline None & 10 & 0 \\
Normal rabbit globulin & 10 & 22 \\
Immune rabbit globulin & 10 & 75 \\
None & 28 & 0 \\
Normal rabbit globulin & 28 & 0 \\
Immune rabbit globulin & 28 & 86.6 \\
None & 50 & 0 \\
Normal rabbit globulin & 50 & 84 \\
Immune rabbit globulin & 50 & 84 \\
\hline
\end{tabular}

* A wound mucoid strain of $S$. aureus was used.

of the RLM strain with an antiserum against the wound strain. It seemed that the results and conclusions of Price and Kneeland ${ }^{1,2}$ had been confirmed; still, we were not ready to conclude that a lack of specificity existed in the capsular antigen simply because all isolates seemed to be of a single type. We concluded instead that the wound-RLM type possibly represented a major capsular type, owing to the widespread occurrence of this type and of antibodies against it in various animal and human sera. In $1968^{10}$ we described the paradoxical behavior of two encapsulated variants of $S$. aureus in mice. One of the variants, the wound strain with which most of our work had been done, was indisputably encapsulated. The other, the Smith diffuse variant, was held to be encapsulated by virtue of its appearance in wet mounts of India ink and its extraordinary virulence for mice. It had never, however, exhibited a positive specific capsular reaction. We definitively established that the Smith variant was encapsulated, because it produced a positive specific capsular reaction in the presence of

TABLe 8

Removal of Passive Protection with Capsular Polysaccharides *

\begin{tabular}{lc}
\hline \multicolumn{1}{c}{ Antiserum } & $\begin{array}{c}\text { Percent } \\
\text { Survival }\end{array}$ \\
\hline None & 0 \\
Immune rabbit globulin & 63 \\
Absorbed immune rabbit globulin & 33 \\
None & 0 \\
Human globulin & 46 \\
Absorbed human globulin & 8 \\
None & 0 \\
Immune rabbit globulin & 80 \\
Absorbed immune rabbit globulin & 10 \\
\hline
\end{tabular}

* A wound mucoid strain of $S$. aureus was used. 
TABLE 9

SPECific Capsular Reactions of Staphylococci *

\begin{tabular}{lcc}
\hline \multicolumn{1}{c}{ Strain } & $\begin{array}{c}\text { Antiserum Prepared Against } \\
\text { Smith Strain }\end{array}$ \\
\hline Wound & Encapsulated Wound & - \\
Wound SCV & - & + \\
Smith diffuse & - & - \\
Smith compact & - & + \\
\hline
\end{tabular}

* Tests were carried out with hyperimmune rooster anti-S. aureus serum.

hyperimmune rooster serum. The conditions under which this reaction is elicited with the Smith diffuse variant differ from those under which it occurs with the wound strain. The latter strain exhibits capsules optimally in 4- to 8-hour broth cultures, while the Smith diffuse variant does so in 18-hour plate cultures. Attempts to produce specific capsular reactions with heterologous sera produced the results shown in TABLE 9. The antisera produced specific capsular reactions only with the homologous strains; thus, it seemed reasonable to postulate that these were two serologically distinct capsular types. These two capsular types behaved differently in virulence tests carried out in mice when hog gastric mucin was used as a virulence enhancer; the results of these tests are shown in TABLE 10. The Smith diffuse variant was virulent in Swiss albino mice, whereas the wound encapsulated variant was not. We postulated the carriage of encapsulated $S$. aureus by mice as a possible explanation of the anomalous behavior of the two strains. Throat and rectal swabs from mice yielded coagulasepositive $S$. aureus from $61.5 \%$ of 60 mice, making a total of $45 S$. aureus strains. Two of the strains isolated were found to be naturally encapsulated and of the wound type, so the mouse sera were examined to ascertain the incidence of capsular antibodies. The results of this examination are shown in TABLE 11: $55 \%$ of the mice had capsular antibodies against the wound encapsulated strain. This prompted an examination of 40 additional mouse sera, in order to ascertain the simultaneous incidence of wound and Smith capsular antibodies in the same mouse (TABLE 12). The table shows that none of the 40 mice appeared to have Smith capsular antibodies, whereas $32.5 \%$ had wound anticapsular antibodies. We postulated that the behavior of the two encapsulated strains in Swiss albino mice was due to the lack of resistance to the Smith diffuse variant and the presence of a high degree of resistance to

TABLE 10

LD $D_{51}$ Estimations of ENCAPSUlated $S$. aurelis in Mice

\begin{tabular}{lcc}
\hline \hline \multicolumn{1}{c}{ Strain } & $\mathrm{LD}_{* 1}^{* *}$ & $95 \%$ Confidence Limits \\
\hline Smith diffuse & 12 & $4-32$ \\
Wound mucoid & 550,000 & $350,000-850,000$ \\
\hline
\end{tabular}

${ }^{*} \mathrm{LD}_{\mathrm{i} u s}$ and $95 \%$ confidence limits are expressed as the number of staphylococci necessary to produce a $50 \%$ kill, calculated after a 14-day observation period. 
TABLE 11

incidence of Capsular Antibodies in Mice *

\begin{tabular}{lcc}
\hline \multicolumn{1}{c}{ Test Strain } & Number Positive & Percentage \\
\hline Wound mucoid ${ }^{*}$ & $33 / 60$ & 55 \\
Autologous S. aureus $t$ & $0 / 60$ & 0 \\
\hline
\end{tabular}

* This was determined from the specific capsular reaction, using the encapsulated wound $S$, aureus strain as test organism.

$\dagger$ This was determined by using the autologous $S$. aureus strain from each mouse.

the wound variant. Since the mice carried encapsulated $S$. aureus of the wound type and a significant number possessed capsular antibodies that reacted with this type, it was also postulated that the avirulence of the wound encapsulated strain could be explained on this basis.

The studies that provided evidence for the possible existence of two distinct capsular types led to the isolation of 13 mucoid strains of $S$. aureus from mice. All were coagulase-positive and fermented mannitol anaerobically. Any of the mucoid strains that failed to react in the specific capsular reaction with antiserum against the wound or Smith encapsulated $S$. aureus strains were selected for the preparation of vaccine to be used to immunize rabbits. The results of specific capsular reaction tests carried out with homologous and heterologous antiserum are shown in TABLE 13. At least four capsular types were revealed by these tests. The wound mucoid strain, Smith diffuse strain, and naturally encapsulated mouse strains $36 \mathrm{~T}$ and $43 \mathrm{R}$ appeared to be serologically distinct from each other. Strains designated as $47 \mathrm{R}, 50 \mathrm{R}$, and $51 \mathrm{R}$ cross-reacted with antiserum against the 43R strain, and it was concluded that these strains were probably of the same capsular type as $43 \mathrm{R}$. The wound mucoid strain is considered to represent a major capsular type and has been isolated from humans and mice. Capsular antibodies against it have been detected in human, mouse, rabbit, and rooster sera.

The four capsular types we proposed are the wound RLM type, a major type, the Smith diffuse type, and two serologically distinct types isolated from mice, designated as $36 \mathrm{~T}$ and $43 \mathrm{R}$.

Virulence in an organism such as $S$. aureus is most likely multifactorial, but there is felt to be evidence that encapsulation is more common than is

TABLE 12

Further Studies of Anticapsular Antibodies on 40 Additional Mouse Sera

\begin{tabular}{lcc}
\hline Test Strain & Number Positive & Percentage \\
\hline Smith diffuse $*$ & $0 / 40$ & 0 \\
Wound mucoid $\dagger$ & $13 / 40$ & 32.5 \\
\hline
\end{tabular}

* This was determined from the specific capsular reaction, using the encapsulated Smith strain of $S$. aureus.

t This was determined from the specific capsular reaction, using the encapsulated wound mucoid strain of $S$. aureus. 
generally accepted, and that the passive protective properties of antiserum or globulin that contains high titers of capsular antibodies provides evidence that the capsule contributes to virulence, particularly when absorption of these capsular antibodies by capsular polysaccharide significantly reduces the protective properties of such antiserum. Whatever success we have had in relating virulence and encapsulation we attribute to the following: (1) to having a potent capsular antiserum, (2) to the use of young broth cultures of $S$. aureus for specific capsular reactions, and (3) to application of the specific capsular reaction to freshly isolated strains of $S$. aureus, which have been subcultured only once or twice. We can practise colonial selection, as workers with typhoid $\mathrm{Vi}$ antigen do to maintain their cultures, but this works well only with the wound mucoid strain, because it is easy to recognize the mucoid trait. Naturally occurring encapsulated $S$. aureus strains are not necessarily highly mucoid, and subculture on ordinary laboratory media may result in the rapid loss of this trait.

TABLE 13

Specific Capsular Reactions * of Encapsulated S. aureus Strains

\begin{tabular}{lccccccc}
\hline \multicolumn{1}{c}{ Strain } & $\begin{array}{c}\text { Wound } \\
\text { Mucoid }\end{array}$ & $\begin{array}{c}\text { Smith } \\
\text { Diffuse }\end{array}$ & $36 \mathrm{~T}$ & $43 \mathbf{R}$ & $47 \mathbf{R}$ & $50 \mathrm{R}$ & $51 \mathrm{R}$ \\
\hline Wound mucoid & + & - & - & - & - & - & - \\
Smith diuse & - & + & - & - & - & - & - \\
$36 \mathrm{~T}$ & - & - & + & - & - & - & - \\
$43 \mathbf{R}$ & - & - & - & + & + & + & + \\
47R & - & - & - & + & + & + & + \\
$50 \mathrm{R}$ & - & - & - & + & + & + & + \\
$51 \mathrm{R}$ & - & - & - & + & + & + & + \\
\hline
\end{tabular}

* Antiserum produced by hyperimmunization of rabbits.

\section{REFERENCES}

1. Price, K. M. \& Y. A. Kneeland. 1954. A mucoid form of Micrococcus pyogenes var. aureus which shows capsular swelling with specific immune serum. J. Bacteriol. 67: 472-475.

2. Price, K. M. \& Y. A. Kneeland. 1956. Further studies of the phenomenon of capsular swelling of Micrococcus pyogenes var, aureus in the presence of immune serum. J. Bacteriol. 71: 229-230.

3. Bigger, J. W., C. R. Boland \& A. R. O'Meara. 1927. Variant colonies of Staphylococcus aureus. J. Pathol. Bacteriol. 30: 261-269.

4. Alexander, H. E., G. Leidy \& C. MacPherson. 1946. Production of types $\mathrm{a}, \mathrm{b}, \mathrm{c}, \mathrm{d}, \mathrm{e}$, and $\mathrm{f} H$. influenzae antibody for diagnostic and therapeutic purposes. J. Immunol. 54: 207-211.

5. WILEY, B. B. 1961. A new virulence test for Staphylococcus aureus and its application to encapsulated strains. Can. J. Microbiol. 7: 933-943.

6. Frappier, G. \& S. SonEA. 1953. Staphylococcie experimentale de l'embryon de poulet de gravite constante proportionelle aux doses de bacteries. Compt. Rend. Soc. Biol. Montreal 12: 86-88.

7. Miller, L. C. \& M. L. Tainter. 1944. Estimation of the $\mathrm{ED}_{50}$ and its error by 
means of logarithmic-probit graph paper. Proc. Soc. Exp. Biol. Med. 57: 261264.

8. Ehrenworth, L. \& H. Baer. 1956. The pathogenicity of Klebsiella pneumoniae for mice: The relationship to the quantity and rate of production of type specific capsular polysaccharide. J. Bacteriol. 72: 713-717.

9. WILEY, B. B. 1968. Capsule size, coagulase production, and egg virulence among certain strains of Staphylococcus aureus. Can. J. Microbiol. 14: 685-689.

10. WiLeY, B. B. \& N. H. MAverakis. 1968. Virulent and avirulent encapsulated variants of Staphylococcus aureus. J. Bacteriol. 95: 998-1002.

\section{Discussion of the Paper}

Dr. D. Mirelman: Do you know anything about the sensitivity to antibiotics of the encapsulated strains?

DR. WILEY: I don't have the data. We do have antibiograms on these organisms. All I can say in an offhand way is that the antibiograms are representative of the antibiograms you would expect of those obtained from staphylococci isolated in hospitals. In other words, they have multiple antibiotic resistances. That statement doesn't apply to those that occur naturally in animals, because I can't make any statement about them.

DR. M. TAgER: Once you have such a strain, are you able to maintain it easily in a laboratory, or does it tend to revert or lose its capsule?

DR. WILEY: The wound strain is easy to maintain, as a number of people in this room know who have received cultures of this strain from me. Since its consistency is like that of chewing gum, when you touch a needle to it the whole colony comes up, and you can literally break your needle trying to shake the colony off into broth.

The naturally occurring strains of encapsulated staphylococci are not of this character (I want to underline and emphasize this), and it is very difficult to maintain them. We now resort to lyophilization after the second subculture, and file them away, rather than risking loss of the capsular strain by subcultivation. We don't feel that we can be successful in colonial selection, because they do not always exhibit mucosity as our prototype wound strain does.

Dr. BENNETT (Food and Drug Administration, Washington, D.C.): Out of the 21 carriers that were positive, what serological tests did you use to measure the anticapsular antibody?

Dr. Wiley: The test we use is the one that we've advocated as the most definitive test: that is, the specific capsular reaction. The old term is the Quellung reaction.

Dr. BenNetT: Have you used the hemagglutination inhibition test?

Dr. WILEY: No, we haven't. We used the hemagglutination inhibition test only as a means of measuring the secretion of capsular material into the extracellular environment. This is a fairly cumbersome test, and we prefer screening with the specific capsular reaction.

Actually, as Dr. Ekstedt said, it is a very simple procedure. Anyone can do it. One has a suspension of organisms; one simply puts a loop of organisms into a drop of antiserum and a drop of methylene blue, places a cover slip over them, waits a few minutes, and looks at them under a microscope. For screening it's simplicity itself. The difficult part is to get an antiserum with a high titer, but that can be done with vigorous immunization. 